\title{
Neuromyelitis Optica Spectrum Disorder and Neurosyphilis Coexist in A Chinese Woman
}

\section{Fulan Shan ${ }^{1,2}$, Youming Long ${ }^{1,2}$, Yongxiang Fan ${ }^{1,2}$, Mengyu Chen ${ }^{1,2}$, Yangbo Zheng ${ }^{1,2}$ and Cong Gao ${ }^{1,2^{*}}$}

${ }^{1}$ Key Laboratory of Neurogenetics and Channelopathies of Guangdong Province and The Ministry of Education of China, Institute of Neuroscience and the Second Affiliated Hospital of Guang Zhou Medical University, P.R.China

${ }^{2}$ Department of Neurology, the Second Affiliated Hospital of Guang Zhou Medical University, P.R.China

*Corresponding author: Cong Gao, Key Laboratory of Neurogenetics and Channelopathies of Guangdong Province and The Ministry of Education of China, Institute of Neuroscience and The Second Affiliated Hospital of Guang Zhou Medical University, 250\# Chang gang east Road, Guang Zhou, 510260 Guangdong Province, P.R.China, Tel: +86-020-3415-3147; Fax: +86-020-3415-3147; E-mail: smilegaocong@126.com

Rec date: Jul 18, 2014; Acc date: Oct 24, 2014; Pub date: Oct 27, 2014

Copyright: ( 2013 Shan F, et al. This is an open-access article distributed under the terms of the Creative Commons Attribution License, which permits unrestricted use, distribution, and reproduction in any medium, provided the original author and source are credited.

\begin{abstract}
Background: Neuromyelitisoptica spectrum disorder (NMOSD) is a series of central nervous system diseases with positive aquaporin-4 antibody. And neurosyphilis is a manifestation of the late syphilis. Although Neuromyelitisoptica (NMO) following syphilis has been previously reported, transverse myelitis and neurosyphilis in the same patient with positive aquaporin-4 antibody has never been mentioned.
\end{abstract}

Method: We presented the coexistence of NMOSD and syphilis in a 72-year-oldChinese woman and analyzed the relationship of these two diseases. The pertinent literatures were also reviewed.

Result: Previous studies showed that syphilitic myelitis might be more frequent in male than in female and it tended to be asymptomatic. However our case was a woman who experienced acute attack, with positive AQP4 antibody. Therefore, her myelitis occurrence mainly associated with AQP4 antibodies autoimmunity, and neurosyphilis might be an asymptomatic episode in our case. Although there was no evidence that treponema pallidum subspecies pallidum involved in the pathogenesis of NMO, it seemed that anti-syphilitic treatment was helpful to attenuate disability in our present case.

Conclusion: Anti-NMO and anti-syphilitic treatment should be used together to treat the patient with both NMOSD and neurosyphilis.

Keywords: Myelitis; Neuromyelitisoptica spectrum disorder; Neurosyphilis; Aquaporin-4

\section{Introduction}

Transverse myelitis (TM) is an inflammatory demyelinating disorder of the spinal cord that has various manifestations [1]. TM has several subtypes according to origin but, in China, most of them are associated with neuromyelitisoptica (NMO) and multiple sclerosis (MS) [1]. However, the exact etiologies of inflammatory demyelinating $\mathrm{TM}$ are unclear and the details of their pathogenesis are unknown. NMO immunoglobulin G (IgG), selectively targeting to the antigen of aquaporin-4 (AQP4) that localizes in the central nervous system (CNS) microvessels, pia, subpia, and Virchow-Robin space has been considered as an biomarker to some TM [2], which is defined as NMO spectrum disorder (NMOSD). Previous studies have revealed this autoantibody as an important contributor to TM pathology.

Viral or bacterial infections $[3,4]$ may be prodromal factors of TM, commonly stimulating an inappropriate immune attack in spinal cord. On the other hand, many infections can induce direct neuronal invasion, resulting in spinal cord injury. Neurosyphilis has traditionally been divided into distinct syndromes. Sometimes, it involves in the spinal cord that may manifest itself as tabesdorsalis, meningomyelitis, spinal vascular syphilis, hypertrophic pachymeningitis, and even development of extramedullary location [5].

Although NMO following syphilis has been previously reported [6,7], TM and neurosyphilis in the same patient with positive AQP4 antibody has never been mentioned. We present the revelation of NMOSD in a 72-year-old Chinese woman and the pertinent literatures are reviewed.

\section{Case Report}

The patient was a 73-year-old Chinese woman, who developed TM in July, 2013. She experienced the severe attack with quadriplegia, sphincter dysfunction, and sensory disturbance, but vision was normal. Three days later, she was transferred to our hospital. Her initial expanded disability status scale (EDSS) was 8.5. She had no feculent sexual behavior and could not recall any symptoms of primary or secondary syphilis.

T2-weighed spinal magnetic resonance imaging (MRI) showed a lesion extending from the third cervical cord to the fifth thoracic cord (C3-T5) without any enhancement. Cranial MRI showed a high T2 signal and fluid attenuated inversion recovery (FLAIR) abnormality involving the pons, corpus callosum, bilateral ependyma around the bilateral ventricle, and the septum pellucidum without any enhancement (Figure 1). Somatosensory evoked potential was 
abnormal. But visual-evoked potential and brain-stem auditory evoked potential were normal.
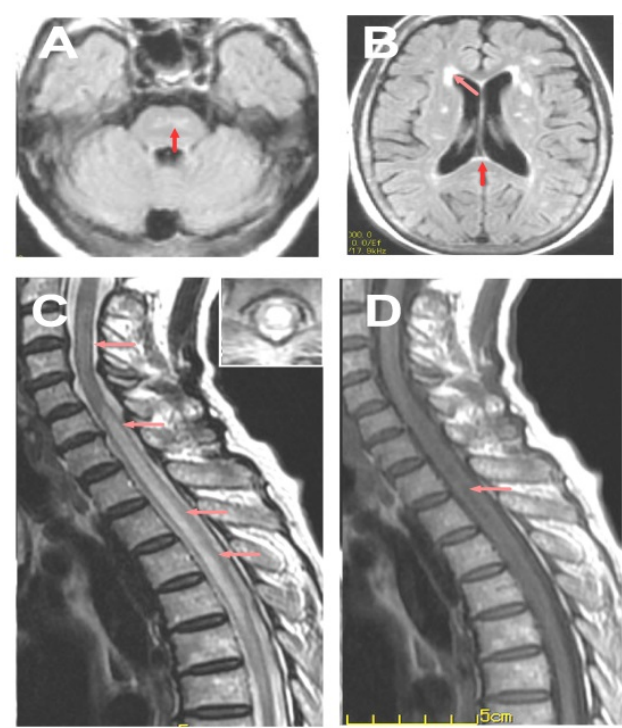

Figure 1: MRI features of the case. A: Lesion in Pons (arrow); B: Brain lesions around the bilateral ventricle (arrow) and in corpus callosum (arrow); C: T2-weighed spinal MRI showed extensive lesion in the cervical and thoracic cord (C3-T5); D: T1-weighed spinal MRI showed hypointensity mainly around the central canal (arrow).

On the lab test, she was tested positive for antinuclear antibody (1:1000), anti-mitochondrial antibody M2 subtype (1:10000), antiRo-52 antibody (1:10000), anticardiolipin antibody-IgM (1:1) and anticardiolipin antibody-IgA (1:1). Her erythrocyte sedimentation rate was $64.0 \mathrm{~mm} / \mathrm{h}$, anti-thyroglobulin antibody was $140.2 \mathrm{KIU} / \mathrm{L}(0-50$ $\mathrm{KIU} / \mathrm{L})$, and antithyroid peroxidase antibody was $44.94 \mathrm{KIU} / \mathrm{L}(0-35$ KIU/L). Anti-AQP-4 antibody was detected in both of the serum (1:10000) and cerebral spinal fluid (1:1000) by cell-based assay. Blood tests for syphilis were positive for toluidine red unheated serum test (TRUST) (1:8 titers) and reactive in specific treponema pallidum particle agglutination assays (TPPA). A lumbar puncture was performed with normal opening pressure. The cerebral spinal fluid (CSF) had elevated cellular count $(15 \times 106 / \mathrm{L})$ with slightly elevated protein $0.67(0.12-0.40 \mathrm{~g} / \mathrm{L})$, normal glucose, and chloride. There were no bacteria, fungi and mycobacterium tuberculosis. CSF tests for syphilis were positive for TRUST (1:1 titer) and reactive in specific TPPA.

Based on these results, she was diagnosed as NMOSD and neurosyphilis. She was treated with intravenous methylprednisolone ( $1 \mathrm{~g}$ daily for three days) and intravenous immunoglobulin G (20 g daily for five days). After the treatment, her motor and sensory disturbance did not improve. On neurological examination, the muscle strength in upper limbs was in grade 4 and that in lower limbs was grade 2. Superficial sensations were severely impaired in lower limbs. Two weeks later, she received the penicillin treatment for neurosyphilis in another hospital. About two months later, her muscle strength in four limbs was improved with 5 of EDSS. The titers were decreased for AQP4 antibodies (1:100) and TRUST (1:1) in serum.

\section{Discussion}

Although the coexistence of NMO and syphilis has been noted in some previous case reports, to our knowledge, it is the first time to describe NMOSD patients with neurosyphilis. In our case, the diagnosis of these two disorders is clear. The revised diagnostic criteria proposed for NMO requires myelitis, optic neuritis, and at least two of three supportive criteria [8]: (1) contiguous spinal cord MRI lesion extending over $\geq 3$ vertebral segments; (2) brain MRI not meeting diagnostic criteria for multiple sclerosis; (3) NMO-IgG seropositive status. Although our patient did not meet above absolute criteria, according to recent new consensus [9], she clearly had definite NMOSD with positive AQP4 antibodies in both of serum and CSF. In spite of a "gold standard" for the diagnosis of neurosyphilis is not available, the serologic tests, clinical findings and examination of CSF play a major role, especially the testing of CSF. Treponemapallidum haemagglutination/TPPA/ microhemaglutination for Treponemapallidum and/or fluorescent treponemal antibodyabsorption tests positive and increased number of mononuclear cells or positive venereal disease research laboratory (VDRL)/rapid plasma reagin (RPR) in CSF are used in the diagnosis of neurosyphilis. A reactive VDRL-CSF test is generally considered definitive evidence of neurosyphilis. Although it's very high specificity, it is difficult to develop VDRL test in most of hospital. The TRUST is a routine serological test for syphilis in China. It is reported that the specificity of the TRUST in neurosyphilis was $100 \%$, which is the same as the VDRL [10]. Therefore, the diagnosis of neurosyphilis is also definite to our present patient because of the positive TPPA and TRUST in CSF.

Infectious causes to spinal cord include viral, bacterial, mycobacterial, fungal, and parasitic agents, commonly are treatable [11]. The spectrum of neurosyphilis is broad and may manifest as meningitis, dementia, stroke, and progressive myelopathy. Syphilitic involvement of the spinal cord may have various manifestation, including tabesdorsalis, meningomyelitis, spinal vascular syphilis, hypertrophic pachymeningitis [5]. Syphilitic myelitis is a rare manifestation of syphilis and a rare cause of myelopathic syndromes in general [11]. On the other hand, we have carried out a literature search for the years 1949-2013 in the context of our case study and found about 25 case reports of syphilitic myelitis (Table 1). It appears that syphilitic myelitis may be more frequent in the male than in the female. However, the most common form of neurosyphilis currently diagnosed is asymptomatic, as our case is a woman who experienced acute attack, with very high sero-AQP4 antibodies titers, and high CSF AQP4 antibodies titers. Therefore, her myelitis occurrence maybe mainly associated with AQP4 antibodies autoimmunity. Although potential infections, such as helicobacter pylori $[4,12]$, were associated with anti-AQP4 antibody positive status, no evidence has showed that syphilis infection was involved in the AQP4 autoimmunity. Therefore, neurosyphilis may be an asymptomatic and isolated episode in our case. When NMOSD meets neurosyphilis, it is critical to differentiate which is the main cause. Certainly, although there is no evidence that treponemapallidum subspecies pallidum involved the pathogenesis of $\mathrm{NMO}$, it seems that anti-syphilitic treatment is helpful to attenuate disability to our present case. Therefore, combined treatment of immunosuppressant and anti-syphilis is recommended in such patients.

In conclusion, TM and neurosyphilis in a patient with positive aquaporin-4 antibody is extremely rare. Although neurosyphilis may be an asymptomatic and isolated episode, combined treatment of immunosuppressant and anti-syphilis is recommended. 


\begin{tabular}{|c|c|c|c|c|c|c|}
\hline Author & Year & $\begin{array}{l}\text { Se } \\
x\end{array}$ & $\begin{array}{l}\mathrm{Ag} \\
\mathrm{e}\end{array}$ & Spinal lesions & $\begin{array}{l}\text { AID } \\
S\end{array}$ & Therapy \\
\hline Stratton EK [13] & 1949 & $\mathrm{~F}$ & NA & NA & No & $P G$ \\
\hline Wigfield AS [14] & 1970 & M & 42 & NA & No & $P G$ \\
\hline Fisher M, et al. [15] & 1977 & M & 58 & NA & No & PG \\
\hline $\begin{array}{l}\text { Harrigan EP, et al. } \\
\text { [16] }\end{array}$ & 1984 & $\mathrm{~F}$ & 51 & NA & No & $P G$ \\
\hline Talbot MD, et al. [17] & 1985 & $M$ & 34 & NA & No & PG \\
\hline Tashiro K, et al. [18] & 1987 & $M$ & 31 & T3-T4 & No & $P G$ \\
\hline $\begin{array}{l}\text { Lowenstein DH, et al. } \\
\text { [19] }\end{array}$ & 1987 & M & 26 & NA & No & $P G$ \\
\hline Janier M [20] & 1988 & M & 26 & NA & No & $P G$ \\
\hline P M Terry, et al. [21] & 1989 & M & 31 & NA & No & $P G$ \\
\hline Berger JR [22] & 1992 & $\mathrm{~F}$ & 33 & T8 & Yes & $P G$ \\
\hline $\begin{array}{l}\text { Nabatame } \mathrm{H} \text {, et al. } \\
\text { [23] }\end{array}$ & 1992 & M & 46 & $\begin{array}{l}\text { thoracic spinal } \\
\text { cord }\end{array}$ & No & $P G$ \\
\hline Strom T, et al. [24] & 1994 & $M$ & 28 & T5 & No & $P G$ \\
\hline \multirow[t]{3}{*}{ John JF, et al. [25] } & 1977 & $\mathrm{~F}$ & 49 & NA & No & PG \\
\hline & 1977 & M & 45 & NA & No & PG \\
\hline & 1977 & $\mathrm{~F}$ & 65 & NA & PG & PG \\
\hline $\begin{array}{l}\text { Srivastava } \mathrm{T} \text {, et al. } \\
{[26]}\end{array}$ & 2000 & M & 32 & T5-T12 & No & PG \\
\hline $\begin{array}{l}\text { Bulundwe } K K \text {, et al. } \\
\text { [27] }\end{array}$ & 2000 & M & 53 & T3-T6 & No & $\begin{array}{l}\text { Benzyl- } \\
\text { PG }\end{array}$ \\
\hline Tsui EY, et al. [28], & 2002 & $\mathrm{~F}$ & 52 & $\begin{array}{l}\text { whole spinal } \\
\text { cord }\end{array}$ & No & PG \\
\hline Kikuchi S, et al. [29] & 2003 & M & 36 & $\begin{array}{l}\text { Whole spinal } \\
\text { cord }\end{array}$ & No & $P G$ \\
\hline $\begin{array}{l}\text { Matijosaitis V, et al. } \\
{[30]}\end{array}$ & 2006 & M & 38 & $\mathrm{T6} 6-\mathrm{T7}$ & No & $P G$ \\
\hline $\begin{array}{l}\text { Chilver-Stainer L, et } \\
\text { al. [31] }\end{array}$ & 2009 & M & 46 & $\mathrm{~T} 6$ - the conus & No & $P G$ \\
\hline \multirow[t]{3}{*}{ Kayal AK, et al. [32] } & 2011 & M & 35 & Conusmedullaris & No & NA \\
\hline & 2011 & M & 38 & NA & No & NA \\
\hline & 2011 & $\mathrm{~F}$ & 30 & $\begin{array}{l}\text { whole spinal } \\
\text { cord }\end{array}$ & No & NA \\
\hline Mebrouk Y [33] & 2011 & M & 40 & $\mathrm{~T} 2-\mathrm{T} 4$ & No & PG \\
\hline
\end{tabular}

Table 1: Case-reports: syphilitic myelitis in previous literatures (19492011)

\section{Acknowledgments}

This project was supported by the plan of China Postdoctoral Science Foundation Grant (2012M521586), Guangdong Natural
Science Foundation (S2013010016262), the Science and Technology plan project of Guangdong Province (2012B031800240), and the plan of GuangZhou Medical University (2012C46).

\section{References}

1. Li R, Qiu W, Lu Z, Dai Y, Wu A, et al. (2011) Acute transverse myelitis in demyelinating diseases among the Chinese. J Neurol 258: 2206-2213.

2. Lennon VA, Wingerchuk DM, Kryzer TJ, Pittock SJ, Lucchinetti CF, et al.(2004) A serum autoantibody marker of neuromyelitisoptica: distinction from multiple sclerosis. Lancet 364: 2106-2112.

3. Ren Z, Wang Y, Duan T, Patel J, Liggett T, et al. (2012) Crossimmunoreactivity between bacterial aquaporin- $Z$ and human aquaporin-4: potential relevance to neuromyelitisoptica. J Immunol 189: 4602-4611.

4. Long Y, Gao C, Qiu W, Hu X, ShuY,et al. (2013) Helicobacter pylori infection in NeuromyelitisOptica and Multiple Sclerosis. Neuroimmunomodulation 20: 107-112.

5. Berger JR (2011)Neurosyphilis and the spinal cord: then and now. J NervMent Dis 199: 912-913.

6. Vidal MF, Garcia SV, Gonzalez J, Richart JC(1989) Devic's syndrome during secondary syphilis. An Med Interna 6: 497-498.

7. Wilcox RA, Burrow J, Slee M, Craig J, Thyagarajan D (2008) Neuromyelitisoptica (Devic's disease) in a patient with syphilis. MultScler 14: 268-271.

8. Wingerchuk DM, Lennon VA, Lucchinetti CF, Pittock SJ, Weinshenker BG (2007)The spectrum of neuromyelitisoptica. Lancet Neurol 6: 805-815.

9. Fujihara K, Sato DK (2014) AQP4 antibody serostatus: Is its luster being lost in the management and pathogenesis of NMO. Neurology 81: 1186-1188.

10. Jiang Y, Chen X, Ma X, Yang Y, Peng F, et al. (2011) The usefulness of toluidine red unheated serum test in the diagnosis of HIV-negative neurosyphilis. Sex Transm Dis 38: 244-245.

11. Chilver-Stainer L, Fischer U, Hauf M, Fux CA, Sturzenegger(2009) M. Syphilitic myelitis: rare, nonspecific, but treatable. Neurology 72: 673-675.

12. Yoshimura S, Isobe N, Matsushita T, Yonekawa T, Masaki K, et al. (2013) Distinct genetic and infectious profiles in Japanese neuromyelitisoptica patients according to anti-aquaporin 4 antibody status. J NeurolNeurosurg Psychiatry 84: 29-34.

13. Stratton EK (1949)Meningovascular myelitis in early syphilis. Calif Med 70: 209.

14. Wigfield AS (1970)Tabesdorsalis of sudden onset associated with possible transverse myelitis. Br J Vener Dis 46: 262-263.

15. Fisher M, Poser CM(1977) Syphilitic meningomyelitis. A case report. Arch Neurol 34: 785.

16. Harrigan EP, McLaughlin TJ, Feldman RG (1984) Transverse myelitis due to meningovascular syphilis. Arch Neurol 41: 337-338.

17. Talbot MD, Morton RS (1985)Neurosyphilis: the most common things are most common. Genitourin Med 61: 95-98.

18. Tashiro K, Moriwaka F, Sudo K, Akino M, Abe H (1987) Syphilitic myelitis with its magnetic resonance imaging (MRI) verification and successful treatment. Jpn J Psychiatry Neurol 41: 269-271.

19. Lowenstein DH, Mills C, Simon RP(1987) Acute syphilitic transverse myelitis: unusual presentation of meningovascular syphilis. Genitourin Med 63: 333-338.

20. Janier $M(1988)$ Acute syphilitic myelitis in a young man. Genitourin Med 64: 206.

21. Terry PM, Glancy GR, Graham A (1989)Meningovascular syphilis of the spinal cord presenting with incomplete Brown-Sequard syndrome: case report. Genitourin Med 65: 189-191.

22. Berger JR (1992) Spinal cord syphilis associated with human immunodeficiency virus infection: a treatable myelopathy. Am J Med 92: 101-103. 
Citation: Shan F, Long Y, Fan Y, Chen M, Zheng Y, et al. (2014) Neuromyelitis Optica Spectrum Disorder and Neurosyphilis Coexist in A Chinese Woman . J Mol Biomark Diagn 5: 198. doi:10.4172/2155-9929.1000198

Page 4 of 4

23. Nabatame H, Nakamura K, Matuda M, Fujimoto N, Dodo Y, et al (1992) MRI of syphilitic myelitis. Neuroradiology 34: 105-106.

24. Strom T, Schneck SA. Syphilitic meningomyelitis (1991) Neurology 41: 325-326.

25. John JF Jr, Cuetter AC (1977) Spinal syphilis: the problem of fluorescent treponemal antibody in the cerebrospinal fluid. South Med J70: 309-311.

26. Srivastava T, Thussu A (2000) MRI in syphilitic meningomyelitis. Neurol India 48: 196-197.

27. Bulundwe KK, Myburgh CJ, Gledhill RF(2000) Syringomyelia complicating syphilitic spinal meningitis: a case report. Eur J Neurol 7: 231-236.

28. Tsui EY, Ng SH, Chow L, Lai KF, Fong D, et al.(2002) Syphilitic myelitis with diffuse spinal cord abnormality on MR imaging. EurRadiol 12: 2973-2976.
29. Kikuchi S, Shinpo K, Niino M, Tashiro K (2003) Subacute syphilitic meningomyelitis with characteristic spinal MRI findings. J Neurol250: 106-107.

30. Matijosaitis V, Vaitkus A, Pauza V,Valiukeviciene S, Gleizniene R (2006)Neurosyphilis manifesting as spinal transverse myelitis. Medicina (Kaunas) 42: 401-405.

31. Chilver-Stainer L, Fischer U,Hauf M, Fux CA, Sturzenegger M (2009) Syphilitic myelitis: rare, nonspecific, but treatable. Neurology 72: 673-675.

32. Kayal AK, Goswami M, Das M, Paul B(2011) Clinical spectrum of neurosyphilis in North East India. Neurol India 59: 344-350.

33. Mebrouk Y, Chraa M, McMaughey C, Kissani N (2011)Syringomyelia associated with syphilitic spinal meningitis: real complication or possible association. Spinal Cord 49: 757-760. 